\title{
CORRECTION
}

\section{Correction to: The genetic architecture of Plakophilin 2 cardiomyopathy}

Annika M. Dries, Anna Kirillova, Chloe M. Reuter, John Garcia, Hana Zouk, Megan Hawley, Brittney Murray, Crystal Tichnell, Kalliopi Pilichou, Alexandros Protonotarios, Argelia Medeiros-Domingo, Melissa A. Kelly, Aris Baras, Jodie Ingles, Christopher Semsarian, Barbara Bauce, Rudy Celeghin, Cristina Basso, Jan D. H. Jongbloed, Robert L. Nussbaum, Birgit Funke, Marina Cerrone, Luisa Mestroni, Matthew R. G. Taylor, Gianfranco Sinagra, Marco Merlo, Ardan M. Saguner, Perry M. Elliott, Petros Syrris, J. Peter van Tintelen and Regeneron Genetics Center*, Cynthia A. James, Christopher M. Haggerty and Victoria N. Parikh (D)

Genetics in Medicine (2021) 23:2014; https://doi.org/10.1038/s41436-021-01298-4

Correction to: Genetics in Medicine 2021; https://doi.org/10.1038/ s41436-021-01233-7 published online 12 June 2021

Due to a processing error Cynthia James, Brittney Murray, and Crystal Tichnell were assigned to the wrong affiliation.

Cynthia James, Brittney Murray, and Crystal Tichnell have as their affiliation 5 Division of Cardiology, Department of Medicine, Johns Hopkins University, Baltimore, MD, USA.
In addition Hana Zouk, Megan Hawley, and Birgit Funke were assigned only to affiliation 3; they also have affiliation 4 Department of Pathology, Massachusetts General Hospital, Harvard Medical School, Boston, MA, USA.

The original article has been corrected. 